\section{Validity and reliability of self-reported weight, height and body mass index from telephone interviews}

\author{
Validade e confiabilidade do peso, estatura e \\ índice de massa corporal auto-referidos \\ obtidos por entrevista telefônica
}

\begin{abstract}
${ }^{1}$ Faculdade de Saúde Pública, Universidade de São Paulo, São Paulo, Brasil. 2 Secretaria de Vigilância em Saúde, Ministério da Saúde, Brasília, Brasil.

Correspondence A. Lucca

Faculdade de Saúde Pública, Universidade de São Paulo. Av. Dr. Arnaldo 715, São Paulo, SP 01246-904, Brasil. alessandralucca@terra.com.br
\end{abstract}

\begin{abstract}
The objective of this study was to examine factors associated with the validity of self-reported anthropometric measures. The authors selected 726 adults, aged 40 or older, living in the greater metropolitan region of São Paulo, Brazil. Selfreported weights and heights obtained from telephone interviews were compared to values measured directly by means of a multicenter survey. Mean differences $( \pm S D)$ between self-reported and measured weights and heights among men were $0.54( \pm 0.30 \mathrm{~kg})$ and $1.98( \pm 0.31 \mathrm{~cm})$; while among women, they were $-0.48( \pm 0.23 \mathrm{~kg})$ and $3.97( \pm 0.28 \mathrm{~cm})$, respectively. Sensitivity and specificity to diagnose obesity were $71 \%$ and $98 \%$ for males, and $78 \%$ and $96 \%$, for females, respectively. There was good agreement between measured and self-reported weights and body mass index (BMI) among both sexes, however, self-reported height was less reliable. Self-reported weight and height obtained from telephone interviews are valid to estimate the obesity prevalence in this population, although systematic bias was found. Thus, it is desirable that researchers develop their own equations depending on the population being studied.
\end{abstract}

Anthropometry; Obesity; Nutritional Status
Alessandra Lucca 1

Erly Catarina Moura ${ }^{2}$

\section{Introduction}

Weight and height are two anthropometric measurements commonly used in research and clinical practice. In developed countries, the frequent utilization of self-reported weight and height in epidemiological studies has been observed in administered questionnaires 1 , self-administered questionnaires 2, and telephone interviews 3,4 .

Self-reported measurements have been used, especially because they favor resource saving and simplify field work. However, the accuracy of selfreported weight and height has been questioned, particularly in clinical practice 5,6.

One of the main advantages of telephone monitoring is its low cost (five to six times cheaper than the cost of home interviews). Moreover it may be implemented in locations where the human and material resources needed to conduct home probability surveys are unlikely to be found 7 .

Many authors have observed self-reported weight underestimation and self-reported height overestimation $3,4,6,8,9,10,11,12,13$. Self-reported weight underestimation is more prevalent among women, whereas self-reported height overestimation is more prevalent among men 8,14 . In general, men overestimate their height, whereas women underestimate it 4,11,12,13,15. A greater proportion of older men tend to overestimate their height in comparison with younger ones $11,12,15$. Overweight individuals tend to underesti- 
mate their weight, while underweight ones tend to overestimate it 5,6,12,13,14,15,16,17,18.

A national literature survey of the last 20 years revealed only five studies assessing self-reported weight and height accuracy in the Brazilian adult population 14,18,19,20,21. These studies suggested high validity, especially among subpopulations with high levels of education and access to health services. No studies on the validity and reliability of self-reported weight and height obtained by telephone interviews were found in the national literature.

This study aimed to analyze the validity and reliability of self-reported weight and height through telephone interviews, develop regression models that are suitable for predicting actual weight and height values, and examine the performance of the predictive models developed.

\section{Methods}

This study was part of the PLATINO project, a multicenter study with a representative sample that includes individuals aged 40 years or older, living in São Paulo's metropolitan area, Brazil. The sampling procedures adopted by the PLATINO project are described by Menezes et al. 22. Data collection occurred between January and May of 2000, and it involved the following three phases: (a) home visits to identify the sample and deliver an official letter explaining the purposes of the study; (b) telephone interviews conducted by the author of this study and a technical assistant qualified to obtain self-reported weight and height; (c) home visits on the arranged date to obtain weight and height measurements, and gather other data used in the PLATINO study.

This study of validity was possible due to the introduction of the telephone interview between thefirsthomevisitand thetakingofmeasurements (anthropometric and spirometric), conducted by the PLATINO project on the second home visit. Participants were not informed, whether on the first visit or during telephone contacts, that they would be weighed and their height measured at the moment of the home interview. Weight was measured in kilograms and the height in centimeters in answer to the questions "How much do you weigh?" and "What is your height without shoes?", respectively. The anthropometric measurements were taken by interviewers previously qualified by the PLATINO project and collected in duplicate for each individual, and the average value was used. Individuals were examined while wearing light clothes and no shoes. Weight was measured by means of a Tanita (USA) electronic scale with a $200 \mathrm{~g}$ precision, and height was mea- sured by means of a SECA (Germany) portable stadiometer with a $0.1 \mathrm{~cm}$ precision. The time interval between the physical examination and the telephone interview was one week and never longer than 15 days.

$72.6 \%$ of the original sample of 1,000 individuals was interviewed and examined. The following individuals were excluded from the study: 40 people who were not aware of their weight and/ or height; 26 people who refused to provide these measurements; 67 people who did not have a telephone or whose informed numbers were either out of service or wrong; 22 people who could not be contacted after 15 telephone calls; and, finally, 93 people whose control files were not faxed by PLATINO. Moreover, 26 individuals who had their weight and height taken prior to the self-reported measurements were also excluded, due to the possibility of self-reported information being influenced by the values that have just been measured. Thus, the final sample resulted from measured anthropometric information obtained by the PLATINO project combined with the self-reported anthropometric information obtained by telephone interviews $(n=726)$.

Independent variables included self-reported weight and height; measured weight and height; self-reported and measured body mass index - BMI (calculated according to self-reported and measured anthropometric measurements); age (continuous variable in years); sex; ethnic group (dichotomized: white and non-white); level of education (labeled in four strata: 0-4 years, 5-8 years, 9-11 years, and 12 years or more). Dependent variables included anthropometric measurements.

\section{Ethical considerations}

As this study involved telephone interviews, informed consent was replaced by verbal consent, obtained when interviewees were contacted by telephone. On these occasions, the interviewees were informed of the research procedure and of the possibility of giving up the study at any time during the interview itself. They were informed that there was no risk or extra harm on their health involved and were assured that all information provided would be treated in complete confidence. The research project was approved by the Ethics Committee at the Public Health University of São Paulo. In spite of the PLATINO project, ethical approval was obtained from the ethical committees of each participating institution. 


\section{Statistical analysis}

Due to the fact that self-reported weight and height validity and reliability may differ between men and women, separate analyses were performed for both sexes. Differences were calculated by subtracting the measured values from weight, height and BMI self-reported values. As a result, negative differences represented an underestimation of the actual value and positive differences represented an overestimation. The paired t test was employed to identify statistically significant differences between measured and self-reported values.

To verify if differences between self-reported and measured weights, heights and BMI varied according to age group, level of education, ethnic group, and weight, height and BMI quartiles, ANOVA was used.

To identify errors and systematic patterns of differentiation between self-reported and measured values, the methodology proposed by Bland \& Altman was used 23 . The concordance correlation coefficient (CCC), proposed by Lin 24 , and the intraclass correlation coefficient (ICC) were used to obtain a summary measure of agreement between two sources of information found in the same individual. The CCC assesses the agreement between two measurements (obtained from the same sample) by measuring the line of equality variation $\left(45^{\circ}\right)$ of the origin (agreement line). The Pearson coefficient was used to assess the linear association between self-reported and measured values. Several studies have used this coefficient to assess agreement between self-reported and measured measurements. However, this procedure can lead to errors 23 . This coefficient was used only for the purposes of comparison of data of this study with other published ones.

Obesity prevalence's obtained from self-reported and measured values (McNemar test) were compared to verify the impact of self-reported measurement errors on the magnitude of obesity. The validity of self-reported values was analyzed through the calculation of sensitivity and specificity of the nutritional status classification, based on self-reported weight and height values. Sensitivity and specificity of obesity, based on self-reported BMI, were calculated, using measured BMI as a comparison standard.

Linear regression analyses were performed to generate equations that could predict actual weight and height from self-reported values. The outcome variables were measured weight and height, and the explanatory variables were self-reported weight and height, sex, age, level of education and ethnic group. In addition, residue analysis was conducted to verify model assump- tions, multicollinearity analyses among independent variables and tests that included interaction terms. Graphic techniques were used in the residue analyses to detect aberrant and/or influential observations (observations that may influence model parameter estimates) and also homocedasticity assumption (constant error variance). Assumption of normal distribution of variables included in the model was verified using normal probability graphs and histograms. Observations considered discrepant (three standard deviations above or below the mean) were excluded for the purpose of obtaining better estimate adjustment. Explanatory variables whose regression coefficients $(\beta)$ were not statistically significant ( $p>0.05$ ) after adjustment for other characteristics were excluded from the model.

To verify the usefulness of equations that can predict actual weight and height, these equations were applied to a population which is different from the one where models came from (Estudo Pró-Saúde). Finally, as the last step of this study, equations that could predict actual weight and height values from self-reported values were generated, using half of the sample originated from the PLATINO project exclusively. These equations were applied to the remaining half of the sample, aiming to verify their usefulness in a comparable population.

\section{Results}

\section{General characteristics}

Mean age $( \pm S D)$ was 54.6 years $( \pm 10.4)$ for men and 53.2 years $( \pm 11.4)$ for women; while mean level of education was 6.4 years $( \pm 5.26)$ and 5.92 years $( \pm 4.56)$ for men and women, respectively.

Variance analysis showed that, on average, self-reported weight was around 500g above measured weight among men, and around 500g below among women. Age and level of education (both $\mathrm{p}<0.05$ ) seem to have influenced the differences between self-reported and measured weights among women exclusively, where it could be observed that the tendency to underestimate the actual weight decreases with age and increases with the level of education. In both sexes, the tendency to underestimate actual weight increases with measured weight and BMI, and the magnitude and error are substantially greater among those with BMI $\geq 30 \mathrm{~kg} / \mathrm{m}^{2}$ (Table 1). Ethnic group seems not have influenced the differences between self-reported and measured anthropometric measurements. 
Mean of the difference between self-reported and measured weight, height and body mass index (BMI), according to demographic variables and measured BMI in men and women aged 40 or older, living in the metropolitan area of São Paulo, Brazil, 2000

\begin{tabular}{|c|c|c|c|c|c|c|}
\hline \multirow[t]{2}{*}{ Variable } & \multicolumn{2}{|c|}{ Weight (kg) } & \multicolumn{2}{|c|}{ Height $(\mathrm{cm})$} & \multicolumn{2}{|c|}{ BMI (kg/m²) } \\
\hline & $\begin{array}{c}\text { Men } \\
(n=321)\end{array}$ & $\begin{array}{l}\text { Women } \\
(n=405)\end{array}$ & $\begin{array}{c}\text { Men } \\
(n=321)\end{array}$ & $\begin{array}{l}\text { Women } \\
(n=405)\end{array}$ & $\begin{array}{c}\text { Men } \\
(n=321)\end{array}$ & $\begin{array}{l}\text { Women } \\
(n=405)\end{array}$ \\
\hline Measured value * & $73.9(15.8)$ & $67.5(15.8)$ & $167(8.0)$ & 155 (6.0) & $26.3(4.8)$ & $28.2(6.2)$ \\
\hline Self-reported value * & $74.5(14.7)$ & $67.0(15.0)$ & $169(9.0)$ & 159 (8.0) & $25.9(4.2)$ & $26.7(6.0)$ \\
\hline Mean of difference ** & $+0.55 \#$ & $-0.48 \# \#$ & +2.0 \#\#\# & $+4.0 \# \#$ & $-0.40 \# \#$ & $-1.49 \# \# \#$ \\
\hline \multicolumn{7}{|l|}{ Age (years) $\star \star \star ~$} \\
\hline $40-49$ & $0.35(0.44)$ & $-1.01 \# \#(0.32)$ & 1.42 \#\# (0.47) & 2.86 \# \# \# $(0.37)$ & $-0.33(0.19)$ & $-1.34(0.19)$ \\
\hline $50-59$ & $-0.05(0.46)$ & $-0.68 \# \#(0.46)$ & 1.29 \#\# (0.51) & 3.30 \#\# (0.47) & $-0.40(0.23)$ & $-1.40(0.25)$ \\
\hline $60-69$ & $1.16(0.85)$ & $-0.36 \# \#(0.39)$ & $3.30 \# \#(0.76)$ & $5.22 \# \#(0.70)$ & $-0.51(0.33)$ & $-1.86(0.26)$ \\
\hline $70-99$ & $2.66(1.24)$ & $1.57 \# \#(0.74)$ & $4.82 \# \#(1.06)$ & $7.55 \# \#$ (1.04) & $-0.38(0.45)$ & $-1.63(0.54)$ \\
\hline \multicolumn{7}{|c|}{ 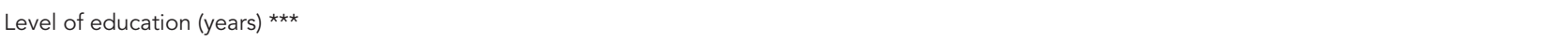 } \\
\hline $0-4$ & $1.07(0.45)$ & $0.13 \# \#(0.30)$ & $2.37(0.46)$ & $4.60(0.42)$ & $-0.32(0.19)$ & $-1.43(0.20)$ \\
\hline $5-8$ & $0.07(0.16)$ & $-0.53 \# \#(0.41)$ & $1.85(0.77)$ & $3.61(0.61)$ & $-0.52(0.28)$ & $-1.36(0.27)$ \\
\hline $9-11$ & $-0.07(0.95)$ & $-2.68 \# \#(0.99)$ & $2.14(0.47)$ & $3.30(0.63)$ & $-0.67(0.39)$ & $-2.20(0.45)$ \\
\hline 12 or more & $0.08(0.84)$ & $-0.72 \# \#(0.38)$ & $0.75(0.48)$ & $2.41(0.36)$ & $-0.17(0.26)$ & $-1.07(0.20)$ \\
\hline \multicolumn{7}{|c|}{ Measured BMI $\left(\mathrm{kg} / \mathrm{m}^{2}\right)$ *** } \\
\hline$\leq 24.9$ & 2.35 \#\#\# (0.47) & 0.29 \#\#\# (0.3) & $1.25(0.56)$ & $3.99(0.52)$ & 0.59 \#\#\# (0.21) & -0.89 \#\#\# (0.21) \\
\hline $25-29.9$ & -0.07 \#\#\# (0.36) & -0.04 \#\#\# (0.29) & $2.22(0.39)$ & $3.88(0.50)$ & -0.72 \#\#\# (0.15) & $-1.25 \# \#(0.19)$ \\
\hline$\geq 30$ & -2.19 \#\#\# (0.78) & -1.77 \#\# (0.54) & $3.10(0.68)$ & $4.03(0.43)$ & -1.89 \#\#\# (0.31) & -2.36 \#\#\# (0.28) \\
\hline \multicolumn{7}{|c|}{ Measured weight quartiles } \\
\hline 1st quartile & 3.21 \#\# (0.72) & $0.46 \# \#$ \# (0.39) & $2.06(0.86)$ & $5.08(0.67)$ & 0.73 \#\# (0.32) & -1.13 \#\#\# (0.28) \\
\hline $2^{\text {nd }}$ quartile & 1.14 \#\# (0.41) & $0.55 \# \#$ \# (0.32) & $1.42(0.50)$ & $3.55(0.52)$ & $-0.03 \# \#$ (0.20) & $-0.86 \# \#$ (0.22) \\
\hline 3rd quartile & $-0.11 \# \# \#(0.43)$ & -0.48 \#\#\# (0.31) & $1.58(0.50)$ & $3.71(0.57)$ & $-0.52 \# \#$ (0.19) & $-1.48 \# \#(0.22)$ \\
\hline 4th quartile & $-2.17 \# \# \#(0.61)$ & $-2.45 \# \# \#(0.66)$ & $2.86(0.51)$ & $3.54(0.45)$ & $-1.74 \# \# \#(0.24)$ & $-2.45 \# \#$ (0.33) \\
\hline \multicolumn{7}{|c|}{ Measured height quartiles } \\
\hline 1st quartile & $1.36(0.67)$ & $0.44(0.43)$ & $3.09(0.87)$ & $5.14+(0.84)$ & $-0.35(0.35)$ & $-1.48(0.37)$ \\
\hline $2^{\text {nd }}$ quartile & $0.79(0.47)$ & $-0.03(0.48)$ & $2.67(0.56)$ & $4.63(0.54)$ & $-0.50(0.20)$ & $-1.48(0.27)$ \\
\hline 3rd quartile & $0.54(0.62)$ & $-1.56(0.52)$ & $1.17(0.45)$ & $3.71(0.42)$ & $-0.18(0.25)$ & $-1.92(0.26)$ \\
\hline $4^{\text {th }}$ quartile & $-0.39(0.59)$ & $-0.53(0.30)$ & $1.20(0.53)$ & $2.62(0.42)$ & $-0.53(0.23)$ & $-0.99(0.17)$ \\
\hline
\end{tabular}

* Mean \pm standard deviation;

** The difference was obtained by subtracting the measured value from the self-reported value. A negative value reflects underestimating and a positive value reflects overestimating;

*** Mean \pm standard error (SE);

$\# p>0.05$;

$\#$ \# $<$ 0.05;

$\# \#$ \#\# 0.001

\section{Self-reported weight versus measured weight}

The tendency to overestimate weight among men (higher concentration of points above the central horizontal line), as well as the tendency to underestimate weight among women (higher concentration of points below the central horizontal line) are initially confirmed (Figure 1). In the case of men, the overestimation of the weight occurs above all until $80 \mathrm{~kg}$, while the underestimation of the weight among women seems to occur independently of weight.
Differences of up to $2 \mathrm{~kg}$ in relation to self-reported weight were observed in $52.3 \%$ of men and $71.8 \%$ of women, thus showing that, on average, women report on their weight more accurately than do men (data not shown).

There was a strong correlation and agreement between self-reported and measured weights among men ( $\mathrm{r}=0.94 ; \mathrm{CCC}=0.94$; $\mathrm{ICC}=0.89$ ), and women $(r=0.96$; $\mathrm{CCC}=0.95$; $\mathrm{ICC}=0.92)$.

For both sexes, self-reported weight was the strongest predictor of weight discrepancy. Among men, the discrepancy between self-reported and 
Figure 1

Scatter plots of the differences between self-reported and measured weights versus the mean of measured and self-reported weights. Horizontal lines represent the mean difference and $95 \%$ limits of agreement.

1a) Male - Limits of agreement: $11.02 ;-9.93 \mathrm{~kg} /$ Mean difference: $0.54 \mathrm{~kg}$

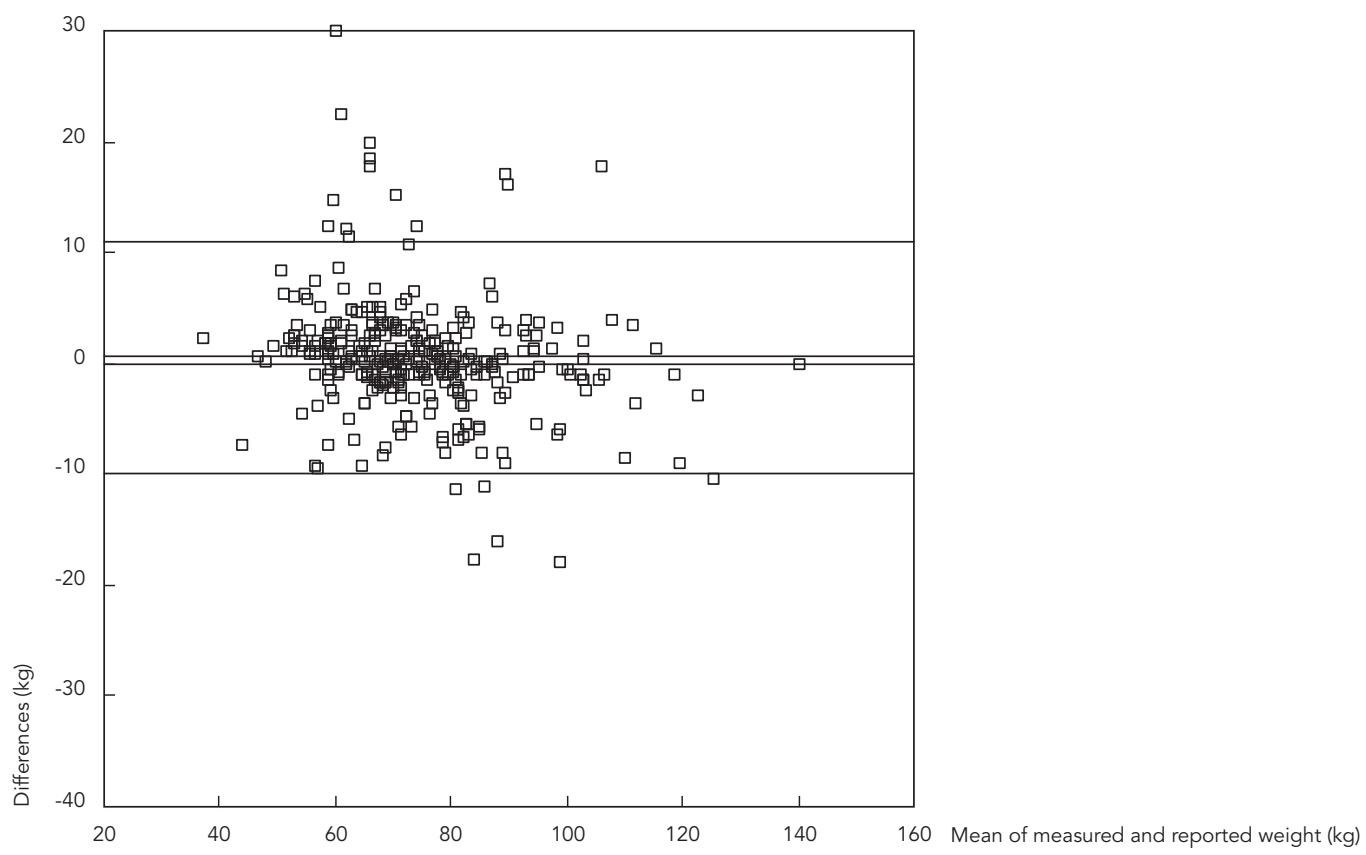

1b) Female - Limits of agreement: 8.42 ; $-9.48 \mathrm{~kg} /$ Mean difference: $-0.48 \mathrm{~kg}$.

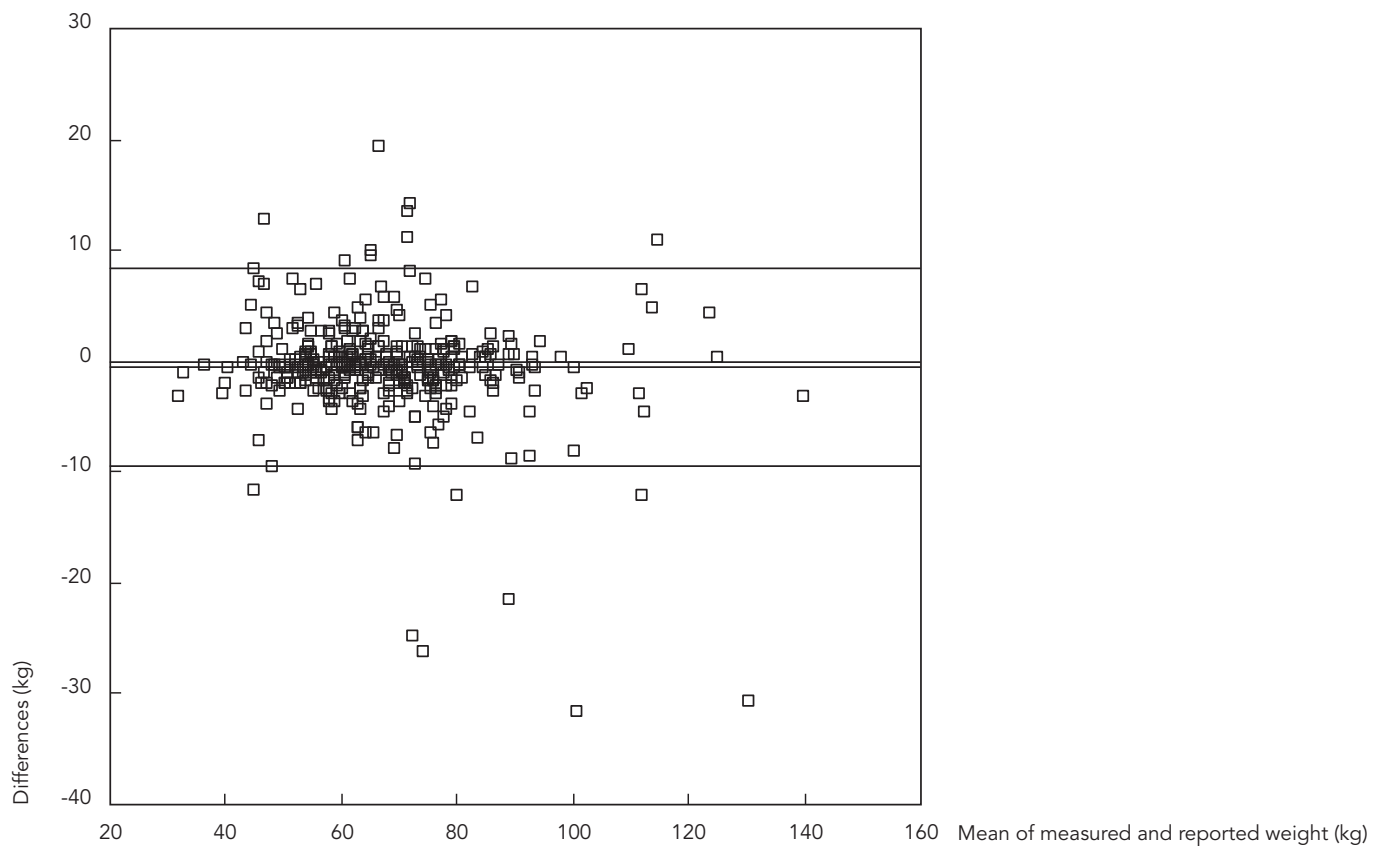


measured weights was significant and positively related to measured weight and level of education, whereas among women, it was significant and positively related to measured weight and negatively related to age.

The equations to predict actual weight by means of self-reported weight among individuals aged 40 years or older were the following:

Men: measured weight $($ in $\mathrm{kg})=-3.34+1.031$ (self-reported weight, in kg) +0.112 (level of education, in years) and $\mathrm{R}^{2}=0.91$;

Women: measured weight $=5.28+0.982$ (selfreported weight, in $\mathrm{kg}$ ) - 0.067 (age, in years) and $\mathrm{R}^{2}=0.93$.

\section{Self-reported height versus measured height}

Self-reported height was overestimated in both sexes, especially among women. Only age and measured height (both $\mathrm{p}<0.05$ ) influenced the differences between self-reported and measured heights significantly. The tendency to overestimate the actual height increased with age and decreased with the increase in height (ANOVA) (Table 1).

Figure 2 shows that height was systematically overestimated in both sexes (higher concentration of points above the horizontal line). On average, self-reported height was around $2 \mathrm{~cm}$ above the measured height among men, and $4 \mathrm{~cm}$ above among women. Discrepancies were greater among women, and, in both sexes, the tendency to overestimate height did not seem to be influenced by the average between self-reported and measured heights.

Height was overestimated to some degree (more than $1.5 \mathrm{~cm}$ ) by $53.9 \%$ of men and $66.9 \%$ of women, thus indicating that, on average, men report their height more accurately than women do. In addition, the magnitude of error was greater among older people.

ICC values were much lower than those observed for weight $(0.68$ for men and 0.61 for women), and they tended to increase with the level of education, especially among women. CCC values tended to increase with the level of education and decrease with age, especially among women.

In the linear regression analysis, the goodness-of-fit assessed by $\mathrm{R}^{2}$ was not as good as in the models for weight $(p<0.001)$. In these models, statistically significant variables were selfreported height, age and level of education, for both sexes.

The equations to predict actual height by means of self-reported height in individuals aged 40 years or older were the following:

Men: measured height (in meters) $=0.481+$ 0.728 (self-reported height, in meters) -0.00097 (age, in years) +0.00184 (level of education, in years) and $\mathrm{R}^{2}=0.70$;

Women: measured height (in meters) $=0.59$ +0.64 (self-reported height, in meters) - 0.0012 (age, in years) +0.0012 (level of education, in years) and $\mathrm{R}^{2}=0.59$.

\section{Self-reported BMI versus measured BMI}

The combined effect of weight underestimation and height overestimation in the BMI composition led to its own underestimation, as well as the prevalence of obesity. Self-reported BMI was lower than that measured in both sexes, totaling $-0.40 \mathrm{~kg} / \mathrm{m}^{2}$ and $-1.5 \mathrm{~kg} / \mathrm{m}^{2}$, among men and women, respectively (Table 1).

Differences between the BMI calculated from self-reported values and that from measured values seem to have been influenced by weight and measured BMI exclusively (both $\mathrm{p}<0.001$ ). The magnitude of error was greater among women, and, in both sexes, it was greater among individuals with $\mathrm{BMI} \geq 30 \mathrm{~kg} / \mathrm{m}^{2}$ (ANOVA) (Table 1 ).

In the graphs proposed by Bland \& Altman 23 (Figure 3), a tendency to underestimate BMI (higher concentration of points below the central horizontal line) can be seen for both sexes. In the case of men, there is a tendency to underestimate self-reported BMI above $25 \mathrm{~kg} / \mathrm{m}^{2}$. In the case of women, there is a similar pattern of underestimation of BMI, independently of the average among the values self-reported and measured; even women with relatively low values of BMI tend to underestimate it. This tendency increases as the BMI increases.

The Pearson coefficient was high $(r=0.90$ among women and $\mathrm{r}=0.87$ among men) and tended to increase at higher education levels. ICC values were higher than 0.74 and tended to increase with the level of education among women. The concordance correlation coefficient was high $(\mathrm{CCC}=0.86$ among men and CCC $=0.87$ among women). In the case of men, there is a tendency to "flat slope syndrome", i.e., overestimation of the actual BMI among those with lower BMI and underestimation among those with higher one. Among the women with measured BMI higher than $20 \mathrm{~kg} / \mathrm{m}^{2}$ there was a clear under estimative of the BMI, however among those with the BMI lower than $20 \mathrm{~kg} / \mathrm{m}^{2}$ the under estimative of such was more discreet.

\section{Impact on the prevalence of obesity}

Prevalence of obesity according to self-reported values (Table 2) was below that obtained by means of measured values. The distribution of nutritional status based on measured values was 
Figure 2

Scatter plots of the differences between self-reported and measured heights versus the mean of measured and self-reported heights. Horizontal lines represent the mean difference and $95 \%$ limits of agreement.

2a) Male - Limits of agreement: $12.77 ;-8.88 \mathrm{~cm} /$ Mean difference: $1.94 \mathrm{~cm}$

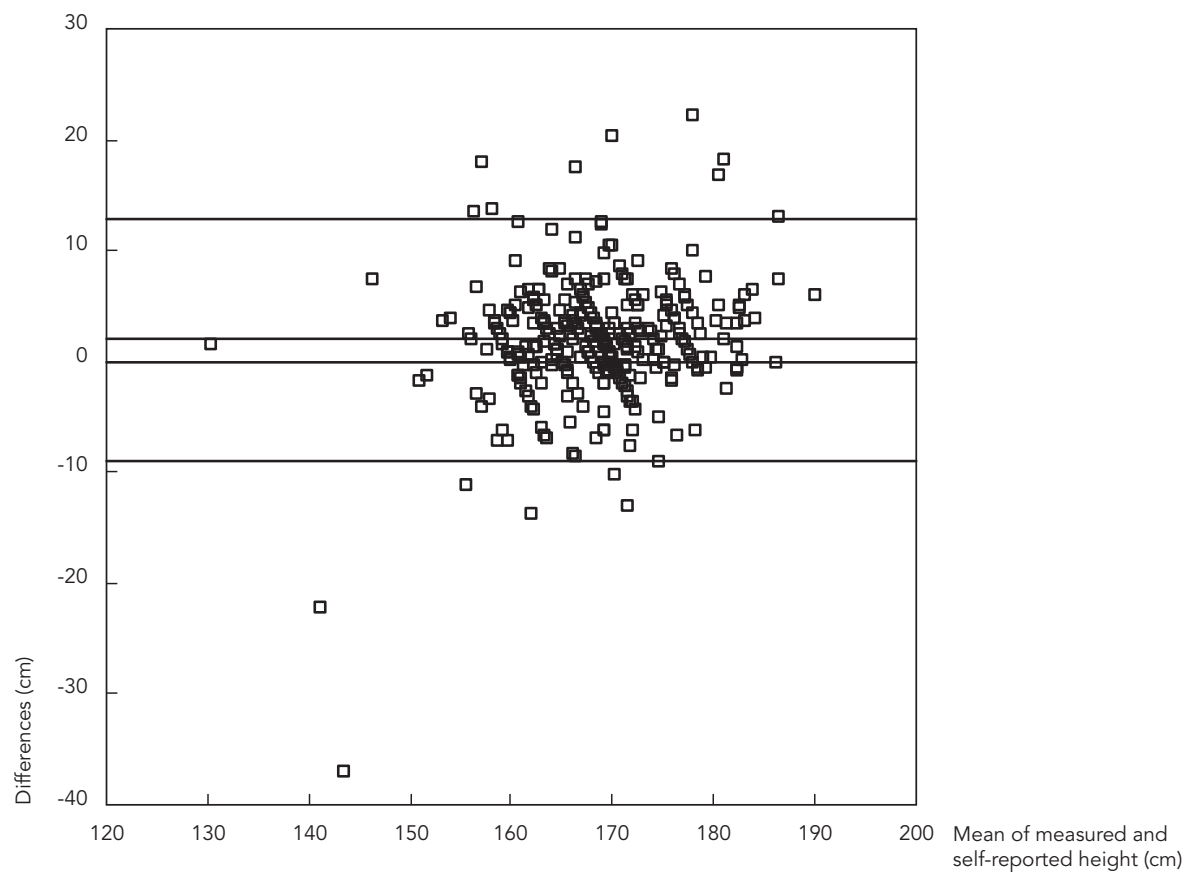

2b) Female - Limits of agreement: $15.06 ;-7.12 \mathrm{~cm} /$ Mean difference: $3.97 \mathrm{~cm}$

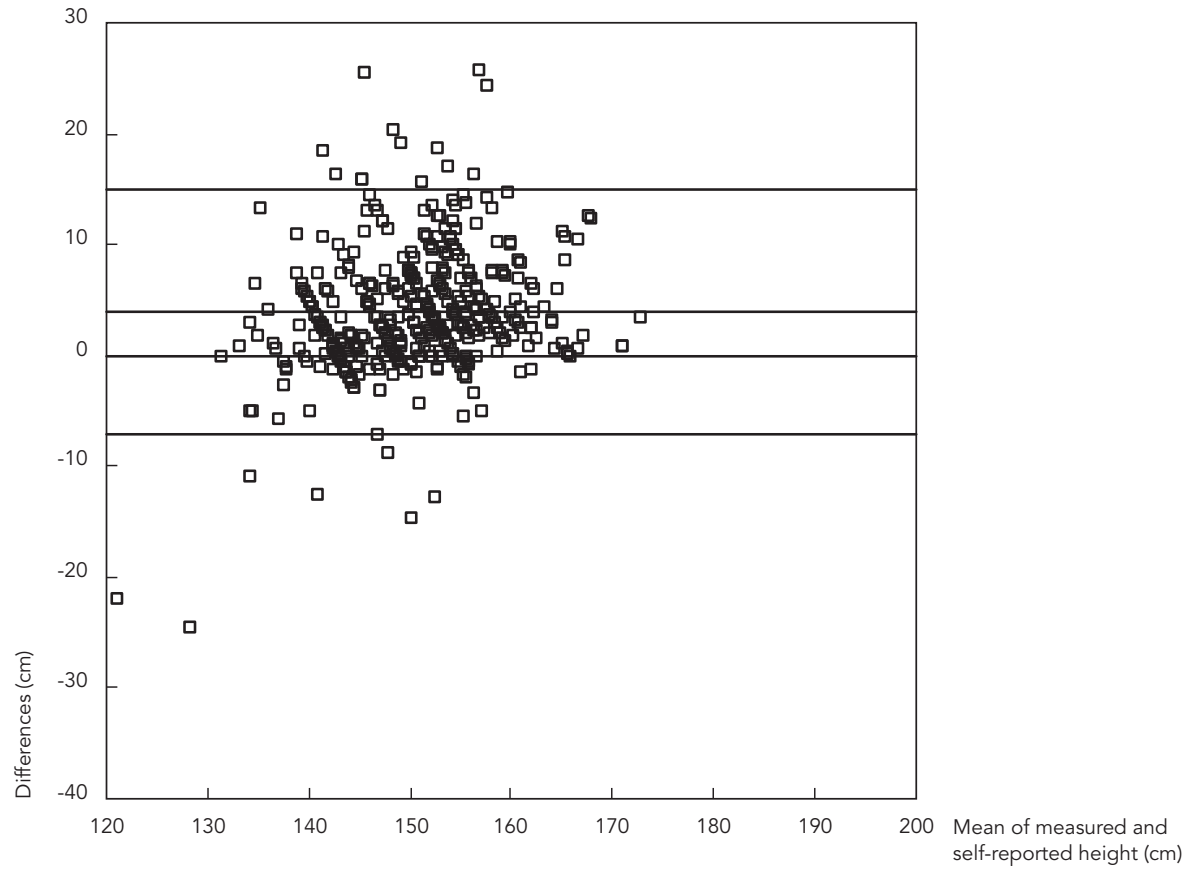


Figure 3

Scatter plots of the differences between self-reported and measured body mass index (BMI) versus the mean of measured and self-reported BMI. Horizontal lines represent the mean difference and $95 \%$ limits of agreement.

3a) Male - Limits of agreement: $4.22 ;-5.00 \mathrm{~kg} / \mathrm{m}^{2} /$ Mean difference: $-0.39 \mathrm{~kg} / \mathrm{m}^{2}$.

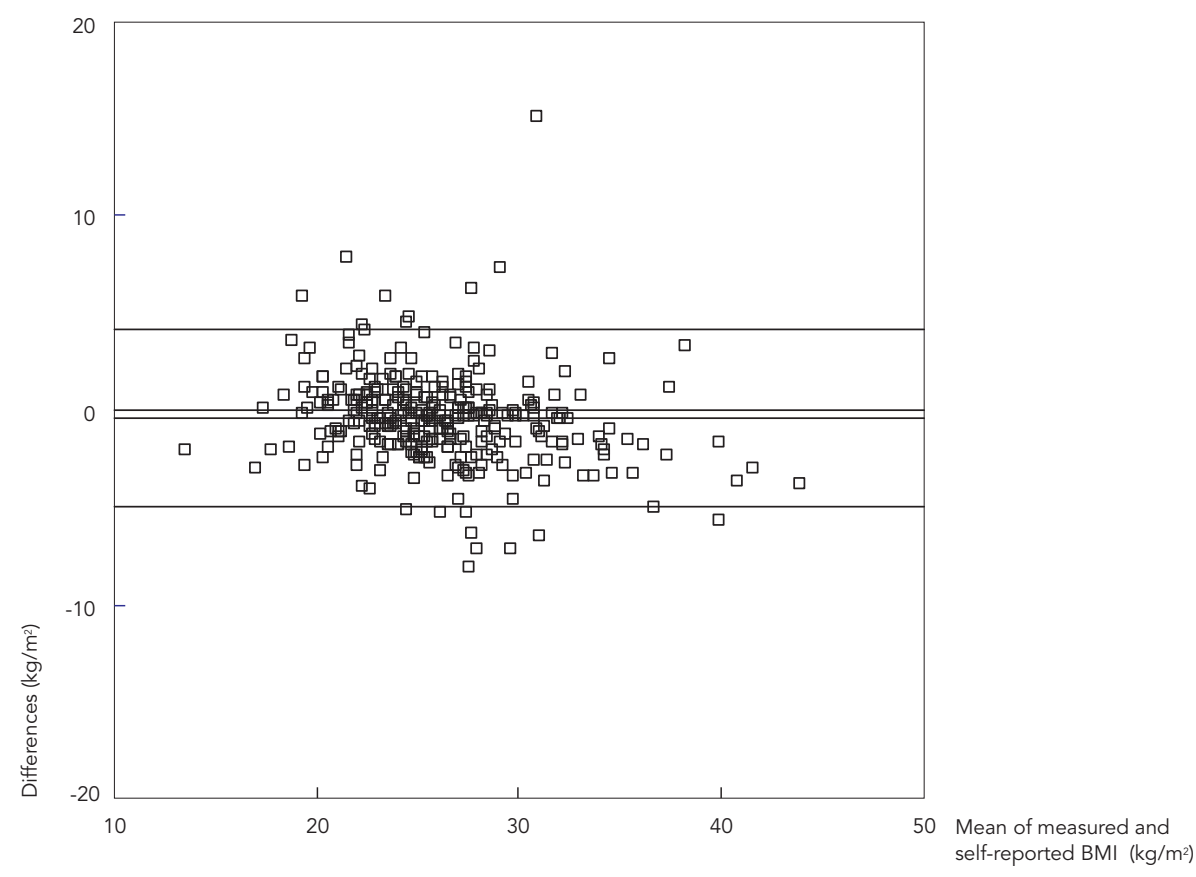

3b) Female - Limits of agreement: $3.90 ;-6.87 \mathrm{~kg} / \mathrm{m}^{2} /$ Mean difference: $-1.48 \mathrm{~kg} / \mathrm{m}^{2}$.

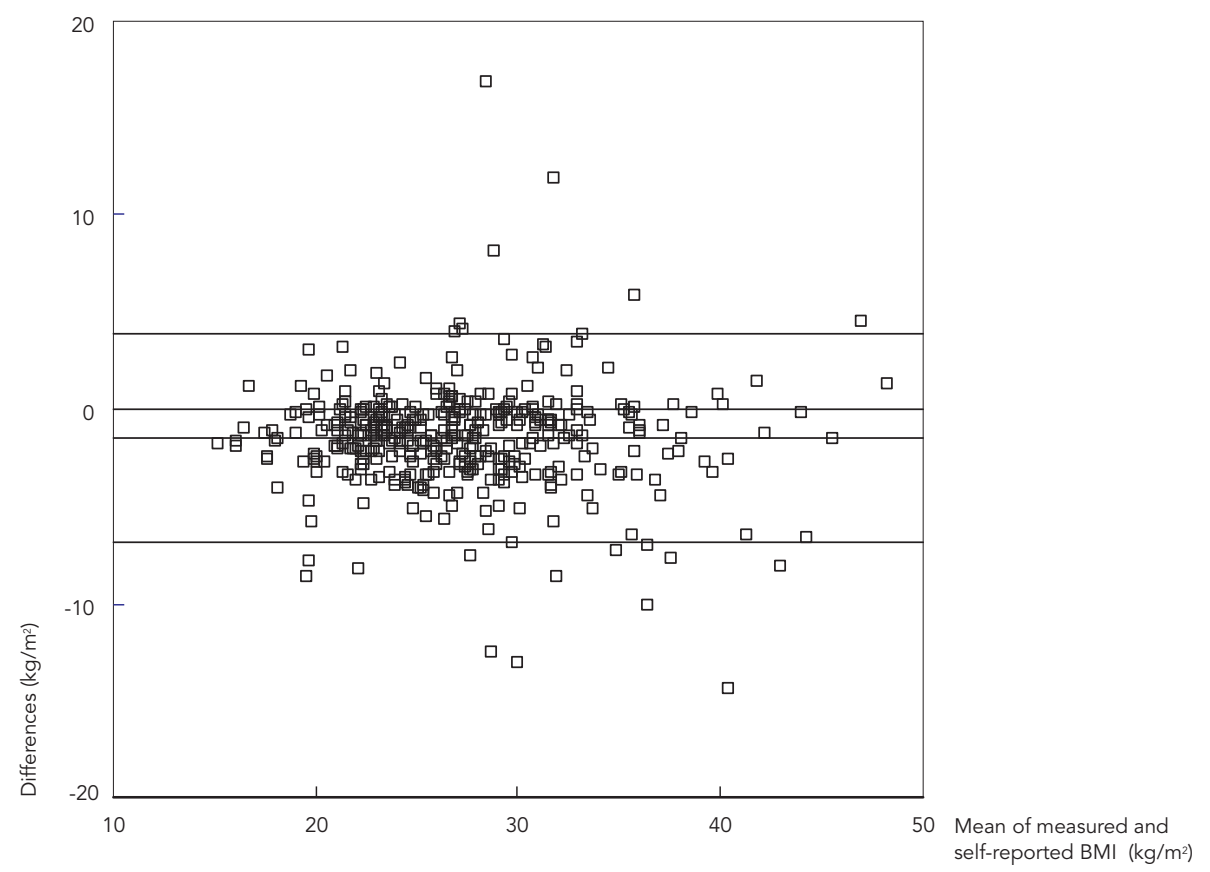


Prevalence of obesity (body mass index $-\mathrm{BMI} \geq 30 \mathrm{~kg} / \mathrm{m}^{2}$ ), based on self-reported and measured values; and test values to diagnose obesity, based on self-reported values.

\begin{tabular}{lcc}
\hline & Men $(\mathbf{n}=\mathbf{3 2 1})$ & Women $(\mathbf{n}=\mathbf{4 0 5})$ \\
\hline Prevalence of obesity (\%) & & 25.4 \\
Based on self-reported values & 15.9 & 31.8 \\
$\quad$ Based on measured values & 18.4 & \\
Test values (\%) & & 71.3 \\
Sensitivity & 78.0 & 96.0 \\
Specificity & 98.1 & 89.3 \\
Positive predictive value & 90.2 & 87.7 \\
Negative predictive value & 95.2 & \\
\hline
\end{tabular}

statistically different from that calculated according to self-reported values (McNemar's test $\mathrm{p}<0.001)$, among both men and women. Specificity (98\% and $96 \%)$ and sensitivity $(78 \%$ and $71 \%$ ) of the diagnosis of obesity, according to selfreported measures, were high among men and women, respectively.

\section{Application of self-reported weight and height correction models to a population which is different from the one from which the models came}

Aiming to verify the usefulness of regression models originating from this study (PLATINO project), predict actual weight and height from the measured values, and use predictive values to calculate the prevalence of obesity, equations developed in 1,808 individuals aged 40 years or older and who were participating in another study (Estudo Pró-Saúde) were tested.

In both sexes, the prevalence of obesity measured (17.8\% among men and $23.2 \%$ among women) was statistically different from the prevalence of obesity calculated from self-reported values ( $16.5 \%$ among men and $17.2 \%$ among women) and adjusted self-reported values (20.9\% among men and $26.2 \%$ among women) (McNemar test $-\mathrm{p}<0.001)$. Sensitivity to diagnose obesity increased from $26 \%$ to $33 \%$ among men, and from $29.2 \%$ to $44 \%$ among women. Even though sensitivity increased, these values were very low when compared to those found by other studies (71\%). Specificity of the diagnosis of obesity remained very high (> 99\%) after adjustment.

\section{Application of self-reported weight and height correction models, designed from half of the sample, to the remaining half of this sample}

Aiming to verify the usefulness of correction models proposed in populations comparable to the one studied, equations for the correction of self-reported measures, originated from half of the sample, were applied to the remaining half of this sample. Gains in validity, measured by means of the increase in sensitivity to diagnose obesity (from $67.9 \%$ to $71.4 \%$ among men, and from $67.9 \%$ to $83.3 \%$ among women) were observed. After adjustment, self-reported weight and height correction equations did not "eliminate" the underestimation of the prevalence of obesity, induced by self-reported values in both sexes. They decreased the magnitude of error in the prevalence of this problem though, thus approximating the self-reported prevalence of obesity (15.9\% among men and 35\% among women) to its actual prevalence (18.5\% among men and $36.8 \%$ among women). For both sexes, the prevalence of obesity measured differed statistically (McNemar's test: $\mathrm{p}=0.001$ for men and $\mathrm{p}<0.001$ for women) from that obtained through self-reported anthropometric values. However, it did not differ statistically (men: $\mathrm{p}=0.533$; women: $\mathrm{p}=0.092$ ) from that obtained through adjusted self-reported values. Specificity was high $(94 \%)$ for both sexes and remained almost unchanged after adjustment. 


\section{Discussion}

Previously published studies 2,13,14 reported that women tend to underestimate weight and men tend to overestimate it. These results were confirmed by this study, which found weight overestimation among men and underestimation among women of about $0.5 \mathrm{~kg}$, thus indicating a reasonable degree of accuracy when informing weight, however they differ of those found by Silveira et al. ${ }^{20}$, in Rio Grande do Sul State, Brazil, that observed the overestimation of weight in both sex. Our results were also different from other studies that observed an underestimation of weight in both sexes, two of which were conducted in Rio de Janeiro, Brazil, by Chor et al. 19 and Fonseca et al. 18 and other studies conducted in the United States 3,9,10 and Europe 1,4,11,12.

According to Schmidt et al. 14, regardless of the frequency and accuracy of weighing oneself, an erroneous idea of one's body is formed, according to a personally desired body image. Even an individual with accurate knowledge of his/her weight may be led to misreport it to the interviewer due to some personal, psychological need such as the desire to be healthier, or due to cultural factors. This self-reported weight bias, apparently used to follow a culturally ideal standard, is consistent with the existing literature on the theme 5,8,16

Another source of error when reporting weight may be one's unawareness of one's actual weight or even the differences between drugstore scales and home scales, which have a widespread use.

It could be observed that the differences between self-reported and measured weights were influenced by actual weight and BMI. The tendency to underestimate weight increased among individuals who were overweight or obese, in both sexes, but it decreased with age among women. The results from this study were comparable to those from previous studies 4,6,7,12,13,14,15,17,25,26,27.

Among women, level of education was inversely related to accuracy in weight information, a fact consistent with findings from Jalkanen et al. 5. Other American studies also showed that the higher the level of education, the greater the differences between self-reported and measured weights, among both sexes 8,9,16. One possible explanation for the association between higher level of education and greater selfreported error may be the fact that body image and desired weight are culturally determined. Thus, the higher the socio-economic and cultural levels, the more concerned one is about weight excess.
Multiple regression analysis for men revealed that only level of education seemed to be associated with weight error, which explains $90.8 \%$ of the variability of average weight error $(p=0.033)$ in the final model. Among women, only age was found to have this association, thus explaining $93 \%$ of the variability of average weight error ( $\mathrm{p}<0.001$ ) in the final model. Thus, older women tended to underestimate weight less often, or even overestimate it, possibly indicating that older women suffer less social pressure.

A reasonable degree of accuracy of weight information can be deduced from the proportion of individuals who informed their weight with a maximum difference of $2 \mathrm{~kg}$ in relation to their actual weight. These findings are in accordance with two studies conducted in Southern Brazil 14,20 where $61 \%$ to $62 \%$ of individuals studied reported their weight with less than $2 \mathrm{~kg}$ of error, respectively. A lower proportion of satisfactory information (52\%) was found by an American study that also employed telephone interviews 3 .

The ICC between self-reported and measured weights was also high (0.91), though slightly below the results found by Peixoto et al. 21, Chor et al. ${ }^{19},(0.98)$ and Fonseca et al. 18 (0.97) in Brazil, and by Bowlin et al. 10 (0.97) in the United States. The CCC between measured and self-reported weights was high, both among women (0.95) and men (0.94), close to that observed in a Brazilian study by Silveira et al. 20 (0.98).

In the case of height, overestimation of reported information was found among both men (about $2 \mathrm{~cm}$ on average) and women (about $4 \mathrm{~cm}$ on average). The tendency to overestimate height in both sexes was consistent with findings from other studies conducted in Brazil 18,19,20,21 and in developed countries, where interviews were also performed by telephone $3,4,11$ or home survey $1,6,8,9,12,13,14,28$.

The magnitude of error in the overestimation of height was greater among women and this tendency was similar to that observed in other Brazilian studies 18,20 and studies performed by telephone 4,11 . A study conducted by Chor et al. 19 in Brazil did not find relevant differences between measured and self-reported heights.

These differences were influenced by age and measured height value in both sexes. The tendency to overestimate height was greater among shorter individuals, results that are consistent with those found by studies conducted in Brazil 19,21 and other studies conducted in developed countries 4,8,11,12,26. In both sexes, overestimation increased with age $2,3,8,11,16,21$ which can be partly explained by the effects of age 6,16 or by the fact that people do not have their height measured often, even those who receive regular 
medical care 29 . Moreover, height overestimation among men may be due to their reporting their height as measured at the time of military service.

It could be observed, through the multiple linear regression analysis, that the accuracy of self-reported height was negatively influenced by age, and positively influenced by level of education, in both sexes. Stewart 28 also found minor differences between self-reported and measured heights in individuals with higher levels of education among both women and men. Moreover, Rowland 15 found that age was the main predictor of discrepancy between self-reported and measured heights.

On average, the population in this study reported their height less satisfactorily than did the population in Pelotas (Rio Grande do Sul State). In the study by Silveira et al. $20,43 \%$ of men and $27 \%$ of women reported their height with a difference of up to $1 \mathrm{~cm}$ in relation to the measured height, whereas, in this study, only $21.8 \%$ of men and $19.7 \%$ of women reported their height within this range.

The ICC between self-reported and measured heights was reasonable (0.74) in both sexes. Results from this study were lower than those found by Peixoto et al. 21 (0.92 among men and 0.83 among women) and Fonseca et al. 18 (0.94) in Brazil, and by Bowlin et al. 10 (0.98) in the United States. This difference may be explained by the education observed in the population of these two studies.

The CCC between self-reported and measured weights was reasonable among men (0.75) and low among women $(0.60)$, values that were below those found by Silveira et al. 20, 0.93 and 0.71 among men and women, respectively.

Sensitivity in the diagnosis of obesity $(74.5 \%)$ was similar to that found by other studies, one of which was performed in Brazil by Fonseca et al. $18(74 \%)$ and others in the United States by Nieto-García et al. 9 (74\%) and Bowlin et al. 10 (74\%), whose interview was also conducted by telephone. The results from this study were higher than those found by Alvarez-Torices et al. 30 in Spain (55\% for women and $61 \%$ for men), Boström \& Diderichsen 11 in Sweden (55$61 \%$ ) and Stewart et al. 31 in New Zealand (63\%). Specificity to diagnose obesity was $97 \%$, a value similar to that found by Fonseca et al. 18 (98\%) and Schmidt et al. 14 (99\%) in Brazil, and also by other studies performed in developed countries (99\%) 3,9. Maybe part of the differences relating to the quality of the weight and height information among this population and the population of other countries may be explained by the differences in age and education.
In this study, the combined effect of the numerator's underestimation with the denominator's overestimation in the BMI composition led to BMI distribution distortions, effects that were comparable to those found by other studies $1,3,6,9,11,14,30,31$ and in the prevalence of obesity $2,3,30$.

The application of predictive equations in a population that is different from the one which originated the models revealed that these equations were of limited use, once they caused the prevalence of obesity to be slightly closer to the actual prevalence, and the sensitivity to be a little increased. However, the application of correction factors (derived from half of the sample) to the remaining half was useful to make the selfreported prevalence of obesity be closer to the actual prevalence, as well as to improve sensitivity in the diagnosis of obesity. Rowland 15 examined the performance of regression models and found that sensitivity to diagnose obesity and overweight increased after adjustment, however by no more than ten percentage points. According the author, this error to classify the BMI after adjustment can not reflect the reliability.

The degree of obesity was one of the key factors for the differences between measured and self-reported weights, in both sexes. In addition, they were influenced by the level of education among men, and age among women. Age and level of education were found to be associated with error when reporting height, in both sexes.

All self-reported information about weight and BMI (calculated from self-reported values), obtained by means of telephone interviews, showed good agreement and validity when compared to their respective measured values $($ CCC $=0.95$ for weight and CCC $=0.87$ for $\mathrm{BMI})$. However, self-reported height was found to be less reliable (CCC $=0.75$ among men and CCC $=0.60$ among women) when compared to the measured height. There was a high level of agreement between self-reported and measured BMI $(\mathrm{CCC}=0.87$ and ICC $=0.81)$. BMI validity, calculated from self-reported values and assessed by means of high sensitivity (71\%) and specificity (96\%) of the diagnosis of obesity, revealed that the telephone interview is a viable tool to diagnose the prevalence of obesity in this population. For practical and economic reasons, self-reports of height and weight can be used in epidemiologic surveys when objective measurements can not be obtained. However, due to systematic bias found, researchers should be aware of the need to correct this bias.

Finally, results from this study suggest caution when using self-reported height and weight data, as these may lead to underestimation in 
the prevalence of obesity and weight excess, and also to a decrease in sensitivity to diagnose such problems in the population. In addition, they may lead to false conclusions about the magnitude of health problems and biases in associations between diseases.

In analyses where anthropometric factors are primary variables of interest, the study of perfor- mance of self-reported measurements and the testing of calibration equations in a subsample of the population to be analyzed are recommended so as to improve the accuracy of BMI estimates.

\section{Resumo}

O objetivo deste estudo foi investigar os fatores associados com a validade das medidas antropométricas auto-referidas. Estudaram-se 726 adultos, com 40 anos ou mais, residentes na área metropolitana de São Paulo, Brasil. A diferença média $( \pm D P)$ entre peso e estatura auto-referidos e aferidos entre homens foi 0,54 $( \pm 0,30 \mathrm{~kg})$ e 1,98 $( \pm 0,31 \mathrm{~cm})$, respectivamente; enquanto entre mulheres foi de $-0,48( \pm 0,23 \mathrm{~kg})$ e 3,97 ( $\pm 0,28 \mathrm{~cm})$, respectivamente. A sensibilidade e especificidade no diagnóstico da obesidade foram $71 \%$ e $98 \%$ entre homens, e 78\% e 96\%, para mulheres, respectivamente. $O$ peso referido e o índice de massa corporal (IMC) calculados com base no peso e na altura referidos apresentaram boa concordância quando comparadas às suas respectivas aferições. A estatura auto-referida, no entanto, mostrou-se menos confiável. A obtenção da informação do peso e estatura por entrevista telefônica é um método válido para estimar a prevalência da obesidade nesta população, apesar dos vieses sistemáticos encontrados. Aconselha-se que os pesquisadores desenvolvam suas próprias equações baseadas na população a ser estudada.

Antropometria; Obesidade; Estado Nutricional

\section{Contributors}

A. Lucca and E. C. Moura worked together in the writing up of the article.

\section{Acknowledgments}

This study was conducted as part of a collaborative survey between the PLATINO Survey, the Estudo Pró-Saúdé and the School of Public Health at the University of São Paulo. We would like to thank Carlos Augusto Monteiro, Patricia Constante Jaime, Eduardo Faerstein and José Maria Pacheco de Souza for their valuable contributions to the thesis from which this article originated. We also thank Rogério Yokoyama Scalice for his help with editing the English manuscript. 


\section{References}

1. Niedhammer I, Bugel I, Bonenfant S, Goldberg $\mathrm{M}$, Leclerc A. Validity of self-reported weight and height in the French Gazel cohort. Int J Obes Metab Disord 2000; 24:1111-8.

2. Kuczmarski MF, Kuczmarski R, Najjar M. Effects of age on validity of self-reported height, weight, and body mass index: findings from the third National Health and Nutrition Examination Survey, 19881994. J Am Diet Assoc 2001; 101:28-34.

3. Bowlin SJ, Morril BD, Nafziger AN, Jenkins PL, Lewis C, Pearson TA. Validity of cardiovascular disease risk factors assessed by telephone survey: the Behavioral Risk Factor Survey. J Clin Epidemiol 1993; 46:561-71.

4. Paccaud F, Wietlisbach V, Rickenbach M. Body mass index: comparing mean values and prevalence rates from telephone and examination surveys. Rev Epidemiol Sante Publique 2001; 49:33-40.

5. Jalkanen L, Tuomilehto J, Tanskanen A, Puska P. Accuracy of self-reported body weight compared to measured body weight. Scand J Soc Med 1987; 15:191-8.

6. Kuskowska-Wolk A, Karlson P, Stolt M, Rössner S. The predictive reported weight and height. Int J Obes 1989; 13:441-53.

7. Remington PL, Smith MY, Williamson DF, Anda RF, Gentry EM, Hogelin GC. Design, characteristics and usefulness of state-based behavioral risk factor surveillance: 1981-87. Public Health Rep 1988; 103:366-75.

8. Palta M, Prineas RJ, Berman R, Hannan P. Comparison of self-reported and measured height and weight. Am J Epidemiol 1982; 115:223-30.

9. Nieto-García FJ, Busch TL, Keyl PM. Body mass definitions of obesity: sensitivity and specificity using self-reported weight and height. Epidemiology 1990; 1:146-52.

10. Bowlin SJ, Morril BD, Nafziger AN, Jenkins PL, Lewis C, Pearson TA. Reliability and changes in validity of self-reported cardiovascular disease risk factors using dual response: the behavioral risk factor survey. J Clin Epidemiol 1996; 49:511-7.

11. Boström G, Diderichsen F. Socioeconomic differentials in misclassification of height, weight and body mass index based on questionnaire data. Int J Epidemiol 1997; 26:860-6.

12. Gunnell D, Berney L, Holland P, Maynard M, Blane D, Frankel S, et al. How accurately are height, weight and leg length reported by the elderly, and how closely are they related to measurements recorded in childhood? Int J Epidemiol 2000; 29:456-64.

13. Villanueva EV. The validity of self-reported weight in US adults: a population based cross-sectional study. BMC Public Health 2001; 1:11.

14. Schmidt MI, Duncan BB, Tavares M, Polanczyk CA, Pellanda L, Zimmer PM. Validity of self-reported weight: a study of urban Brazilian adults. Rev Saúde Pública 1993; 27:271-6.

15. Rowland ML. Self-reported weight and height. Am J Clin Nutr 1990; 52:1125-33.

16. Pirie P, Jacobs D, Jeffery R, Hannan P. Distortion in self-reported height and weight data. J Am Diet Assoc 1981; 78:601-6.
17. Jeffery RW. Bias in reported body weight as a function of education, occupation, health and weight concern. Addict Behav 1996; 21:217-22.

18. Fonseca MJM, Faerstein E, Chor D, Lopes CS. Validade de peso e estatura informados e índice de massa corporal: Estudo Pró-Saúde. Rev Saúde Pública 2004; 38:392-8.

19. Chor D, Coutinho ESF, Laurenti R. Reliability of self-reported weight and height among state bank employees in Rio de Janeiro. Rev Saúde Pública 1999; 33:16-23.

20. Silveira EA, Araújo CL, Gigante DP, Barros AJD, Lima MS. Validação do peso e altura referidos para o diagnóstico do estado nutricional em uma população de adultos no Sul do Brasil. Cad Saúde Pública 2005; 21:235-45.

21. Peixoto MRG, Benício MHD, Jardim PCBV. Validade do peso e da altura auto-referidos: o estudo de Goiânia. Rev Saúde Pública 2006; 40:1065-72.

22. Menezes AMB, Victora CG, Perez-Padilla R; PLATINO Team. The Platino project: methodology of a multicenter prevalence survey of chronic obstructive pulmonary disease in major Latin American cities. BMC Med Res Methodol 2004; 4:15.

23. Bland JM, Altman DG. Measuring agreement in method comparison studies. Stat Methods Med Res 1999; 8:135-60.

24. Lin LI. A concordance correlation coefficient to evaluate reproducibility. Biometrics 1989; 45: 255-68.

25. Field AE, Aneja P, Rosner B. The validity of selfreported weight change among adolescents and young adults. Obesity (Silver Spring) 2007; 15:235764

26. Larson MR. Social desirability and self-reported weight and height. Int J Obes 2000; 24:663-5.

27. Elgar FJ, Stewart JM. Validity of self-report screening for overweight and obesity. Evidence from the Canadian Community Health Survey. Can J Public Health 2008; 99:423-7.

28. Stewart AL. The reliability and validity of self-reported weight and height. J Chronic Dis 1982; 35:295-309.

29. Ziebland S, Thorogood M, Fuller A, Muir J. Desire for the body normal: body image and discrepancies between self reported and measured height and weight in a British population. J Epidemiol Community Health 1996; 50:105-6.

30. Alvarez-Torices JC, Franch-Nadal J, Alvarez-Guisasola F, Hernandez-Mejia R, Cueto-Espinar A. Self-reported height and weight and prevalence of obesity. Study in a Spanish population. Int J Obes Relat Metab Disord 1993; 17:663-7.

31. Stewart AW, Jackson RT, Ford MA, Beaglehole R. Underestimation of relative weight by use of selfreported weight and height. Am J Epidemiol 1987; 125:123-6.

Submitted on $03 / \mathrm{Feb} / 2009$

Final version resubmitted on 29/Jun/2009

Approved on 01/Oct/2009 